\title{
Expansion and hepatic differentiation of rat multipotent adult progenitor cells in microcarrier suspension culture
}

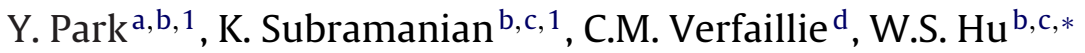 \\ a Department of Biomedical Engineering, University of Minnesota, Minneapolis, MN 55455, USA \\ b Stem Cell Institute, University of Minnesota, Minneapolis, MN 55455, USA \\ c Department of Chemical Engineering and Materials Science, University of Minnesota, Minneapolis, MN 55455, USA \\ ${ }^{\mathrm{d}}$ Interdepartmental Stem Cell Institute, Catholic University Leuven, Leuven, Belgium
}

\section{A R T I C L E I N F O}

\section{Article history:}

Received 5 April 2010

Received in revised form 30 July 2010

Accepted 2 August 2010

Available online xxx

\section{Keywords:}

Microcarrier

Bioreactors

Hepatic differentiation

MAPC

\begin{abstract}
A B S T R A C T
Many potential applications of stem cells require large quantities of cells, especially those involving large organs such as the liver. For such applications, a scalable reactor system is desirable to ensure a reliable supply of sufficient quantities of differentiation competent or differentiated cells. We employed a microcarrier culture system for the expansion of undifferentiated rat multipotent adult progenitor cells (rMAPC) as well as for directed differentiation of these cells to hepatocyte-like cells. During the 4-day expansion culture, cell concentration increased by 85 -fold while expression level of pluripotency markers were maintained, as well as the MAPC differentiation potential. Directed differentiation into hepatocytelike cells on the microcarriers themselves gave comparable results as observed with cells cultured in static cultures. The cells expressed several mature hepatocyte-lineage genes and asialoglycoprotein receptor- 1 (ASGPR-1) surface protein, and secreted albumin and urea. Microcarrier culture thus offers the potential of large-scale expansion and differentiation of stem cells in a more controlled bioreactor environment.
\end{abstract}

(c) 2010 Published by Elsevier B.V.

\section{Introduction}

Advances in stem cell science have opened the possibility that stem cells may be used as therapeutics. Among many organs and tissues for which developing stem cell applications is being pursued, the liver is of particular importance because of the lack of effective therapies for liver failure. Existing treatments for liver failure are limited, and the only real cure is liver cell or organ transplantation. However, the shortage of donor cells and organs makes this option often unavailable for a large number of patients. Hepatocytes isolated from liver have limited proliferation potential in culture, and cultured hepatocytes often very quickly lose their functional attributes. Therefore, there has been intensive research for a source of cells that can proliferate extensively and sustain liver functions in culture. Cultivation of hepatic progenitor cells, immortalization of hepatocytes, and derivation of functional hepatocytes from stem cells are among the more prevalent approaches (Allain et al., 2002; Cai et al., 2000, 2007; Herrera et al., 2006; Rogler, 1997;

Q1 * Corresponding author at: Department of Chemical Engineering and Materials Science, University of Minnesota, 421 Washington Avenue SE, Minneapolis, MN 55455-0132, USA. Tel.: +1 612626 7630; fax: +16126267246.

E-mail address: acre@cems.umn.edu (W.S. Hu).

1 These authors contributed equally to this work and should be considered co-first authors.
Wege et al., 2003; Agarwal et al., 2008; Hay et al., 2008). With the progress in stem cell science, hepatic cells derived from pluripotent stem cells, which are capable of virtually unlimited self-renewal, have great potential to be such a steady cell source.

The liver is the largest organ in the adult body. Any therapeutic application will require a large quantity of cells in the order of $\sim 10^{9}-10^{10}$ cells per treatment. Employing a scalable reactor system can enable a sufficient supply of differentiation competent or differentiated cells to meet such a clinical need. Since the conventional method of expanding and differentiating stem cells in tissue culture plates is labor intensive and difficult to scale up, different culture systems for expansion and differentiation of stem cells have been investigated; rotary culture systems, perfusion culture systems, and stirred suspension systems have been employed for various stem cell cultures (Cameron et al., 2006; Fok and Zanstra, 2005; Gilbertson et al., 2006; Li et al., 2006; Liu et al., 2006; Zhao et al., 2005; Bauwens et al., 2005; Schroeder et al., 2005). Among those systems, stirred suspension culture has the advantage of having been widely used in growing mammalian cells for decades. It also allows high-density culture in a more homogeneous environment, and should allow one to monitor and control culture parameters. Stirred reactor cultures have been used to expand or differentiate hematopoietic stem and progenitor cells (HSPCs), neural stem cells (NSCs), and human and mouse embryonic stem cells (ESCs) grown as embryoid bodies (EBs) (Cameron et al., 2006; Fok and Zanstra, 2005; Gilbertson et al., 2006; Li et al., 2006). For cells grown as

0168-1656/\$ - see front matter (c) 2010 Published by Elsevier B.V. doi:10.1016/j.jbiotec.2010.08.001 
64 monolayers like those on tissue culture plates, microcarriers have the advantage of providing a large surface area for a given reactor volume.

Microcarriers are particles, typically made of cellulose, glass, plastic, or polyester, and usually with diameters of $100-250 \mu \mathrm{m}$. By providing a surface for attachment, they allow anchoragedependent cells to be cultivated in stirred tank bioreactors for large-scale operations. They have been used for cultivation of mouse and human ESCs, mesenchymal stem cells, and umbilical cord stem cells (Fernandes et al., 2007; Chiu et al., 2005; Kehoe et al., 2010; Lock and Tzanakakis, 2009; Nie et al., 2009; Oh et al., 2009; Frauenschuh et al., 2007; Yang et al., 2007). For differentiation applications, microcarriers have been used in a few studies wherein pluripotent stem cells were differentiated into cardiomyocyte-like cells, endoderm progenitor cells, and early trilineage cells (Cameron et al., 2006; Fok and Zanstra, 2005; Bauwens et al., 2005; Lock and Tzanakakis, 2009).

In this study, using rat multipotent adult progenitor cells (rMAPCs) as a model system, we show that microcarrier culture has the potential of being a highly efficient scalable means of stem cell expansion and directed hepatocyte differentiation.

\section{Materials and methods}

\subsection{Establishment and maintenance of rat MAPC line}

One rat MAPC line (rMAPC-1) was used in this study. The isolation of rat MAPC lines has been previously described (Breyer et al., 2006; Ulloa-Montoya et al., 2007). To explain the procedure in short, rMAPC-1 were isolated from bone marrow of the tibia and femur of a 4-week-old female rat (Fischer). Isolated bone marrow cells were plated on 6-well tissue culture plates in MAPC medium at $6 \times 10^{6}$ cells/well and cultured in a $5 \% \mathrm{O}_{2}$ and $5-6 \% \mathrm{CO}_{2}$ incubator at $37^{\circ} \mathrm{C}$. After 4 weeks of culture, hematopoeitic cells were removed using magnetic microbeads against CD45 and Ter119 (Miltenyi Biotec) and the remaining cells are seeded into 96-well plates at 5-10 cells/well. Small and spindle shaped cells that appeared in the wells were subsequently expanded and screened for MAPC phenotype (expression of Oct4, Rex1 and CD31) and tri-lineage (neuroectoderm, endoderm, mesoderm) differentiation potential (Breyer et al., 2006). The established MAPC cell line was maintained at $37{ }^{\circ} \mathrm{C}$ in $5 \%$ oxygen and $5-6 \% \mathrm{CO}_{2}$ at a seeding cell density of 300 cells $/ \mathrm{cm}^{2}$ and passaged using $0.05 \%(\mathrm{w} / \mathrm{v})$ Trypsin-EDTA ( $5 \mathrm{mg} / \mathrm{l}$, Cellgro) every 2 days (Breyer et al., 2006).

\subsection{MAPC medium}

Basal culture medium consisted of a $60 / 40(\mathrm{v} / \mathrm{v})$ mixture of low glucose Dulbecco's Modified Eagle media (DMEM) (Gibco, USA) and MCDB-201 (Sigma) supplemented with $0.026 \mu \mathrm{g} / \mathrm{ml}$ ascorbic acid 3-phosphate (Sigma), linoleic acid bovine serum albumin (LA-BSA, Sigma) (final concentrations of $10^{3} \mu \mathrm{g} / \mathrm{ml}$ BSA and $8.13 \mu \mathrm{g} / \mathrm{ml}$ linoleic acid), insulin-transferrin-selenium (ITS, Sigma) (final concentration $10 \mu \mathrm{g} / \mathrm{ml}$ insulin, $5.5 \mu \mathrm{g} / \mathrm{ml}$ transferrin, $0.005 \mu \mathrm{g} / \mathrm{ml}$ sodium selenite), $0.02 \mu \mathrm{g} / \mathrm{ml}$ dexamethasone (Sigma), $4.3 \mu \mathrm{g} / \mathrm{ml} \beta$-mercaptoethanol. For MAPC expansion, basal medium was supplemented with $2 \%(\mathrm{v} / \mathrm{v})$ qualified fetal bovine serum (Hyclone). In addition, MAPC medium also contained three protein factors: human platelet derived growth factor (PDGF-BB, R\&D) (10 ng/ml), mouse epidermal growth factor (EGF, Sigma) $(10 \mathrm{ng} / \mathrm{ml})$, and mouse leukemia inhibitory factor (LIF) (Chemicon, ESGRO) ( $10^{3}$ units $/ \mathrm{ml}$ ). All media used were also supplemented with $100 \mathrm{IU} / \mathrm{ml}$ penicillin and $100 \mu \mathrm{g} / \mathrm{ml}$ streptomycin (Gibco).

\subsection{Suspension flask culture of MAPC on microcarriers}

Cytodex 1, a crosslinked dextran microbead with N,Ndiethylamioethyl groups on the surface, is microporous, with a void fraction greatly exceeding $90 \%$, and support cell growth on their external surface. Cytodex 1 was purchased from GE Healthcare as dry powders, and the stock was prepared by washing $1 \mathrm{~g}$ of microcarrier powder with PBS for 3-5 times. Swollen beads were sedimented in $100 \mathrm{ml}$ fresh PBS and sterilized by autoclaving.

Prior to suspension culture, microcarriers were washed with low glucose DMEM (Gibco) twice and incubated in MAPC medium for $2 \mathrm{~h}$ at $37^{\circ} \mathrm{C}$. rMAPC cultured on $10 \mathrm{~cm}$ tissue culture plates (NUNC) were washed with PBS. $1 \mathrm{ml} \mathrm{0.05 \% (w/v)} \mathrm{Trypsin-EDTA}$ (Cellgro) was added to each plate and the plates were lightly tapped several times. $5 \mathrm{ml}$ of previously collected culture supernatant was added to each well to neutralize trypsin. The cells were collected, washed, and resuspended in MAPC expansion medium at a concentration of $1.2 \times 10^{6}$ cells $/ \mathrm{ml}$. Cells were added to $12 \mathrm{mg} / \mathrm{ml}$ Cytodex 1 microcarriers at the concentration of $0.6 \times 10^{6}$ cells $/ \mathrm{ml}$ in $2 \mathrm{ml}$ culture medium. The mixture was incubated for $30 \mathrm{~min}$ at $37^{\circ} \mathrm{C}$ to allow initial cell attachment to the beads with occasional shaking of the tube. Then the mixture was transferred into a $98 \mathrm{ml}$ of MAPC expansion medium in a $250 \mathrm{ml}$ spinner flask (Wilbur). The culture was stirred at $70 \mathrm{rpm}$ on a belt-driven magnetic stir plate (Bellco), and maintained at $37^{\circ} \mathrm{C}, 5 \% \mathrm{O}_{2}$ tension and $5 \% \mathrm{CO}_{2}$ for 4 days of expansion culture without any medium change.

\subsection{In vitro directed hepatic differentiation}

MAPC were differentiated into hepatocytes by using a four-step 20 days hepatic differentiation protocol with modifications. For static plate differentiation, cells were inoculated in an ultra-low attachment 24-well plate (Corning) at a starting cell concentration of $1.2 \times 10^{4}$ cells $/ \mathrm{ml}$ with $0.23 \mathrm{mg} / \mathrm{ml}$ Cytodex 1 microcarriers. For stirred suspension differentiation, cells were inoculated in a $250 \mathrm{ml}$ spinner flask at $3.6 \times 10^{4}$ cells $/ \mathrm{ml}$ with $0.6 \mathrm{mg} / \mathrm{ml}$ of Cytodex 1 microcarriers in $100 \mathrm{ml}$ MAPC medium. The cells were expanded in an incubator with $5 \% \mathrm{O}_{2}, 5 \% \mathrm{CO}_{2}$, at $37 \mathrm{C}$. After 2 days of expansion culture, when the cells are $80-90 \%$ confluent on the microcarrier surface, the cells with microcarriers were washed once with PBS and resuspended in $1 \mathrm{ml}$ of hepatic differentiation medium for static plate differentiation or $80 \mathrm{ml}$ of hepatic differentiation medium in a $250 \mathrm{ml}$ spinner flask for stirred suspension differentiation. The composition of differentiation basal medium was the same as basal MAPC medium except that ITS and LA-BSA were at $25 \%$ of the amount in MAPC medium, and the concentration of dexamethasone was at $0.4 \mu \mathrm{g} / \mathrm{ml}$ and the three protein factors and serum were absent. Furthermore, additional protein factors were added as described below. The cytokines and growth factor supplements were added as follows: (i) day 0: Activin A (100 ng/ml) and Wnt3a (50 ng/ml); (ii) day 6: bFGF $(10 \mathrm{ng} / \mathrm{ml})$ and BMP4 $(50 \mathrm{ng} / \mathrm{ml})$; (iii) day 10: FGF8b (25 ng/ml), aFGF (50 ng/ml) and FGF4 (10 ng/ml); (iv) day 14: HGF $(20 \mathrm{ng} / \mathrm{ml})$ and Follistatin $(100 \mathrm{ng} / \mathrm{ml})$. Differentiations were carried out at $21 \% \mathrm{O}_{2}$ and $5 \% \mathrm{CO}_{2} 37 \mathrm{C}$ for 20 days with $50 \%$ media change, corresponding to the differentiation stage, every 2 days.

\section{5. $R N A$ isolation and quantitative real time polymerase chain reaction $(q R T-P C R)$}

Total RNA was isolated from rMAPC cell lysates using RNAeasy microkit (Qiagen) according to instructions provided in the kit. cDNA was synthesized from the extracted RNA using the Superscript III reverse transcriptase (Invitrogen) method. The PCR mix consisted of cDNA samples, SYBR Green Mix PCR reaction buffer (Applied Biosystems) and primers ( $5 \mu \mathrm{M}$ stocks, sequence in 
Table 1

List of primer sequences.

\begin{tabular}{|c|c|c|c|}
\hline Tissue/lineage & Gene & Forward primer & Reverse primer \\
\hline \multirow[t]{3}{*}{ Pluripotency/MAPC } & Oct4 & CTGTAACCGGCGCCAGAA & TGCATGGGAGAGCCCAGA \\
\hline & Rex1 & AAAGCTTTTACAGAGAGCTCGAAACTA & GTGCGCAAGTTGAAATCCAGT \\
\hline & Sall4 & AGAACTTCTCGTCTGCCAGTG & CTCTATGGCCAGCTTCCTTC \\
\hline \multirow[t]{2}{*}{ Definitive endoderm } & Gsc & CCCGGTTCTGTACTGGTGTC & CCCACGTCTGGGTACTTTTGT \\
\hline & Eomes & CCAGACCTTCACCTTCTCAG & GTGTACATGGAATCGTAGTTGTC \\
\hline \multirow[t]{6}{*}{ Hepatic lineage } & Afp & ACCTGACAGGGAAGATGGTG & GCAGTGGTTGATACCGGAGT \\
\hline & $\mathrm{Ttr}$ & CAGCAGTGGTGCTGTAGGAGTA & GGGTAGAACTGGACACCAAATC \\
\hline & Albumin & TCTGCACACTCCCAGACAAG & AGTCACCCATCACCGTCTTC \\
\hline & Aat & CAAACAAGGTCAGCCATTCTC & CAGCATCATTGTTGAAGACCC \\
\hline & Arginase 1 & TATCGGAGCGCCTTTCTCTA & ACATACCGTGGGTTCTTCAC \\
\hline & $\operatorname{Hnf} 4 \alpha$ & AAATGTGCAGGTGTTGACCA & CACGCTCCTCCTGAAGAATC \\
\hline \multirow[t]{3}{*}{ Differentiation markers } & Sox2 & GGCCAACGAATTGGATTCTA & GTTTACTGGCACCACGTCCT \\
\hline & Pax6 & GTCCATCTTTGCTTGGGAAA & TAGCCAGGTTGCGAAGAACT \\
\hline & Flk1 & CCAAGCTCAGCACACAAAAA & CCAACCACTCTGGGAACTGT \\
\hline
\end{tabular}

Table 1). The qRT-PCR reaction was run on a Realplex mastercycler (Eppendorf) using the following program: $50^{\circ} \mathrm{C}$ for $2 \mathrm{~min}, 95^{\circ} \mathrm{C}$ for $10 \mathrm{~min}$, and 40 cycles at $95^{\circ} \mathrm{C}$ for $15 \mathrm{~s}$ and $60^{\circ} \mathrm{C}$ for $1 \mathrm{~min}$ followed by a dissociation protocol to obtain a melting curve. Transcription abundance relative to GAPDH was calculated as $\Delta \mathrm{Ct}$ which is $\mathrm{Ct}$ (transcript of interest) - Ct (GAPDH) and transcript abundance in sample relative to day 0 was calculated as $\Delta \mathrm{Ct}$ (day 0 ) $-\Delta \mathrm{Ct}$ (day of sample).

\subsection{Intracellular staining for Oct4 by flow cytometry}

Trypsinized cells were washed with and suspended in PBS with $3 \%(\mathrm{v} / \mathrm{v})$ serum. After $15-20 \mathrm{~min}$ fixing with $4 \%$ paraformaldehyde (PFA), and $1 \mathrm{~h}$ blocking in SAP buffer (PBS with $0.1 \%(\mathrm{w} / \mathrm{v})$ saponin and $0.05 \%(\mathrm{w} / \mathrm{v})$ sodium azide) supplemented with $10 \%$ donkey serum, cells were incubated for $1 \mathrm{~h}$ with $1 \mu \mathrm{g} / \mathrm{ml} \mathrm{Oct3/4}$ antibody (Santa-Cruz, N19) or Goat IgG isotype control (Jackson Immunoresearch) diluted in SAP buffer followed by incubating with Cy5 labeled anti-goat IgG (Jackson Immunoresearch, 1:500 in SAP buffer) for $30 \mathrm{~min}$. Finally, cells were washed and resuspended in $500 \mu \mathrm{l}$ PBS for flow cytometry analysis using a FACS Calibur (Becton Dickinson).

\subsection{Asialoglycoprotein receptor-1 (ASGPR-1) immunostaining by flow cytometry}

To determine functional maturation, flow cytometric analysis was performed with an anti-asialoglycoprotein receptor-1 (ASGPR-1) antibody. Cells were harvested from the microcarriers by trypsinization. After fixing with 4\% PFA for 20 min and blocking for $1 \mathrm{~h}$ in PBS with $3 \%(\mathrm{v} / \mathrm{v})$ FBS, cells were incubated with antiASGPR-1 antibody (Thermoscientific, 1:10) for $30 \mathrm{~min}$, followed by Alexa 488-conjugated goat anti-mouse IgG secondary antibody (Invitrogen, 1:500) for $30 \mathrm{~min}$. Then cells were washed and resuspended in $500 \mu \mathrm{l}$ PBS for flow cytometry analysis using a FACS Calibur (Becton Dickinson).

\subsection{Phosphoinopyruvate carboxykinase (PEPCK) immunostaining}

Cell-laden-microcarriers were fixed with $4 \%$ PFA for $20 \mathrm{~min}$ and blocked in SAP serum buffer for $1 \mathrm{~h}$. Cells were stained with an
anti-PEPCK antibody in SAP buffer (Santa-cruz, $1: 2000$ ) at $4{ }^{\circ} \mathrm{C}$ for overnight and stained with A488 anti-rabbit IgG (Invitrogen, 1:500) for $30 \mathrm{~min}$. Then cells-microcarriers were washed, resuspended in PBS, and observed under inverted fluorescent microscope (Axiovert 200, Zeiss).

\subsection{Cell viability staining}

The "live/dead viability/cytotoxicity kit" (Invitrogen) was used to stain cells on microcarriers with calcein and ethidium. Component $B$ was added first to DPBS (1:1000) and then component $A$ was added to DPBS with component B $(1: 2000)$. Cells were incubated with the staining solution for $15-30 \mathrm{~min}$ at $37^{\circ} \mathrm{C}$. Cells were washed once with PBS and observed under inverted fluorescent microscope (Axiovert 200, Zeiss). Live and dead cells appear as green and red, respectively.

\subsection{Cell enumeration by nuclei counting}

Microcarriers from $1 \mathrm{ml}$ culture were centrifuged at $500 \mathrm{rpm}$ for $30 \mathrm{~s}$ to remove supernatant. After adding 300-500 $\mu \mathrm{l}$ counting staining solution $(0.1 \%(\mathrm{w} / \mathrm{v})$ crystal violet (Sigma) in $0.1 \mathrm{M}$ citric acid solution (Sigma)), the sample was incubated for $1 \mathrm{~h}$ at $37^{\circ} \mathrm{C}$. Nuclei were released by gentle shearing using a Pasteur pipette in a vertical position. The nuclei were counted with a hemacytometer.

For fixative staining, cells on microcarriers in $1 \mathrm{ml}$ culture were stained by adding a drop or two of fixative staining solution $(0.5 \%$ $(\mathrm{w} / \mathrm{v})$ crystal violet in $40 \%$ ethanol and $60 \% \mathrm{PBS}$ ) for $1-2 \mathrm{~min}$. Stained cells-microcarriers were washed with PBS twice to remove the staining solution from the supernatant.

\subsection{Albumin and urea secretion assay}

The albumin secretion rate was quantified using the rat albumin ELISA quantitation kit (Bethyl) according to instructions provided in the kit. Urea production rate was measured by using QuantiChrom urea assay kit (BioAssay Systems) following the instructions provided in the kit for low urea samples. 
(A)

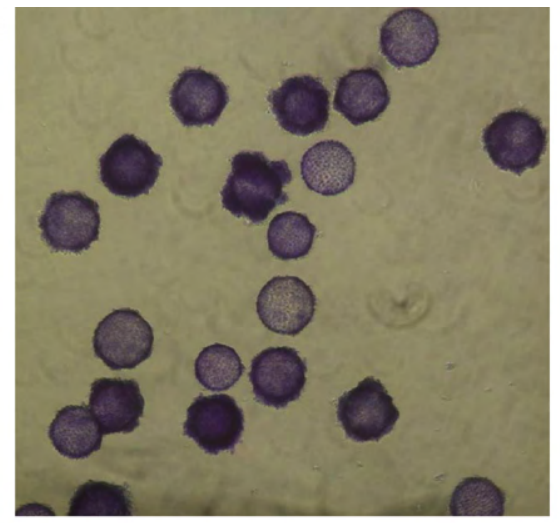

(B)

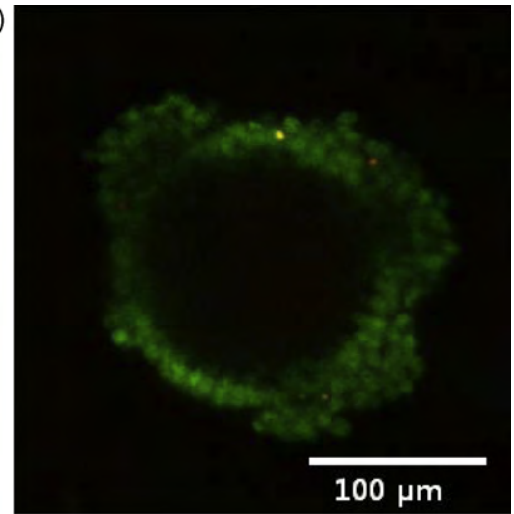

(C)

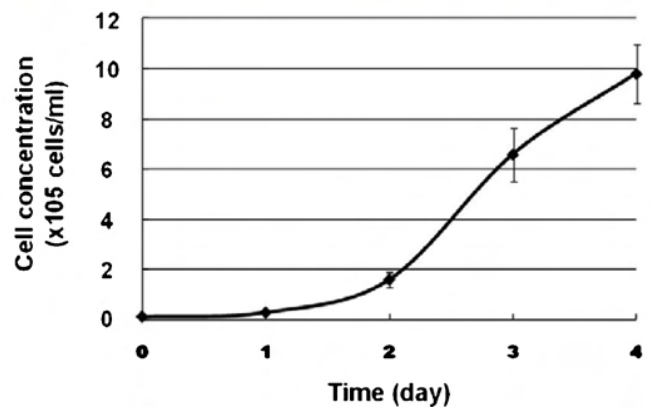

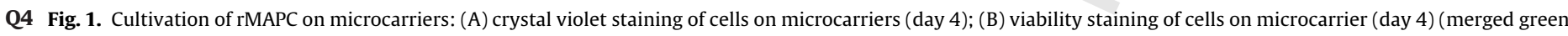

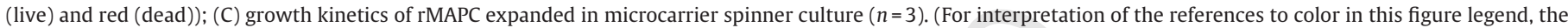
reader is referred to the web version of the article.)

\section{Results}

\subsection{MAPC expansion on microcarriers}

MAPCs were inoculated onto microcarriers at a seeding concentration of $6 \times 10^{5}$ cells $/ \mathrm{ml}$ in $2 \mathrm{ml}$ culture medium and incubated at $37^{\circ} \mathrm{C}$ for not more than $30 \mathrm{~min}$ with occasional shaking in order to increase the frequency of direct contact between microcarriers and cells. Immediately after inoculation, MAPCs attached to the bead surface readily. With the seeding density we used, there were approximately 3-8 cells attached to each bead after $30 \mathrm{~min}$ incubation. Those cell-laden microcarriers were then transferred into a $250 \mathrm{ml}$ spinner flask with a $100 \mathrm{ml}$ working volume of medium. During 4 days of suspension culture, MAPCs proliferated forming multiple layers of cells on most microcarriers (Fig. 1). Calcein-ethidium stain of cells on microcarriers (day 4) show that cells retained high viability for 4 days (Fig. 1B). The cell concentration increased from $1.2 \times 10^{4}$ to $1.0 \times 10^{6}$ cells $/ \mathrm{ml}$ after 4 days of culture equivalent to more than 80 -fold of cell expansion (Fig. 1C). There seemed to be an initial lag of population doubling time (about $21 \mathrm{~h}$ ) during day $0-1$, but this may be overestimated partially because not all cells from the initial cell concentration attach to microcarriers. The population doubling time was about $12 \mathrm{~h}$ during day $1-3$, comparable to that seen when MAPCs were cultivated on a regular tissue culture plates (12-14h). After day 3, MAPC began to form multi-layers, and the doubling time increased to more than $24 \mathrm{~h}$.

\subsection{Maintenance of undifferentiated MAPC on microcarriers in stirred suspension culture}

We evaluated the retention of potency-related markers on MAPCs expanded on microcarriers for 4 days. The expression levels of key MAPC transcripts, Octamer-binding transcription factor 4 (Oct4), Sal like 4 (Sall4), RNA exonulease 1 (Rex1) and CD31, and early differentiation transcripts, $S R Y$ (sex determining region $Y$ )-box 2
(Sox2), Paired box 6 (Pax6), Alpha-fetoprotein (Afp), Flt-related receptor tyrosine kinease (Flk1) were assessed by qRT-PCR on day 0 , day 2 , and day 4. Transcripts of Oct4, Sall4, and Rex1 were sustained at high levels during MAPC proliferation in stirred reactor microcarrier culture (Fig. 2A). CD31 expression was also maintained during that period (Fig. 2A). Expression of genes which are indicative of early differentiation of MAPC into three different lineages (Sox2, Pax6, Afp, and Flk1) were checked. Differentiation was not detected. Pax6 and especially Afp, a gene which is rapidly up-regulated when MAPCs differentiate spontaneously, remained undetected during 4 days of expansion culture (Fig. 2B). Sox2 and Flk1 transcript levels slightly increased on day 4 as the cells form multi-layers on microcarriers (Fig. 2B).

Expression of Oct4 protein, a critical pluripotency-related marker for MAPC, was also analyzed by intracellular Oct4 protein staining and quantified by flow cytometry. Cells were detached from the microcarriers after the expansion culture and stained with an anti-Oct3/4 antibody. Oct4 protein levels were maintained during the microcarrier culture. Approximately $70 \%$ of the cells were Oct $4^{+}$after 4 days (Fig. 2C). The percentage of Oct $4^{+}$cells from microcarrier culture was comparable to the percentage of Oct $4^{+}$ cells (75\%) from conventional static culture on tissue culture plates (Fig. 2C). Our findings demonstrate that MAPC in microcarrier suspension culture without any medium change can be expanded >80-fold while maintaining stable pluripotency gene expression.

\subsection{Hepatocyte differentiation of MAPC on microcarriers}

\subsubsection{Differentiation in static culture}

The feasibility of employing microcarrier in hepatic differentiation was first investigated in static culture. Cells were expanded on microcarriers for 2 days to reach confluent monolayer of cells. MAPC culture medium was then replaced with differentiation medium containing cytokines as described in Section 2. The cell concentration slightly increased initially and then decreased until 

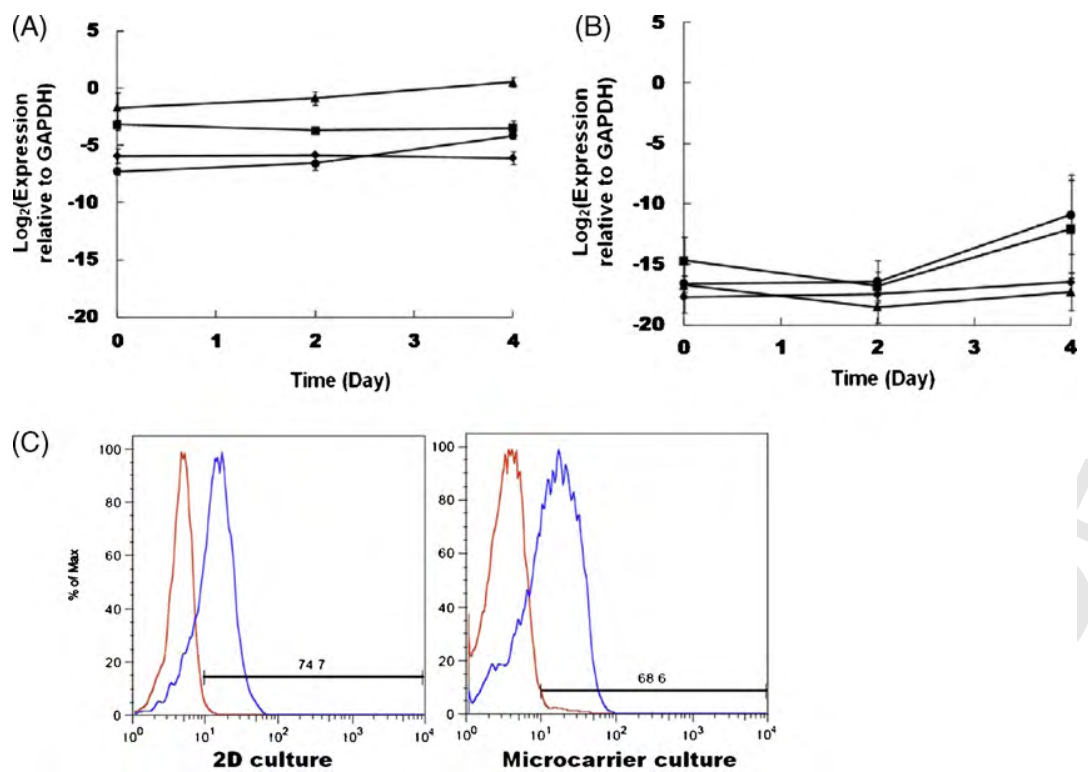

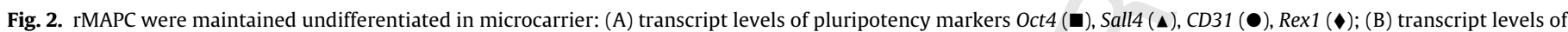

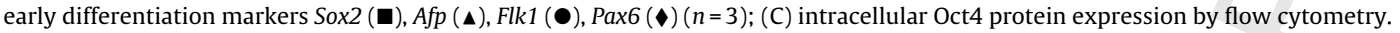

day 10 . As the differentiation proceeded, cell morphology changes were similar to those seen in hepatic differentiation in 2D on tissue culture plates. As the cells proliferated on microcarriers, some started to form bulges, and the bulge size increased towards the end of the differentiation (Fig. 3A). Immunostaining for phosphoinopyruvate carboxykinase (PEPCK), for a gene involved in gluconeogenesis that becomes expressed near birth during development, identified small regions of positive cells (Fig. 3B). The level of liver-specific transcripts was evaluated at the end of hepatic differentiation in $2 \mathrm{D}$ and in $3 \mathrm{D}$ on microcarriers. Hepatic transcripts of alpha-fetoprotein (Afp), transthyretin (Ttr), Albumin, alpha-1-antotrypsin (Aat), tyrosine aminotransferase (Tat), glucose6-phosphate (G6p), microsomal glutathione S-transferase1 (Mgst1), Factor V, Arginase1, and hepatocyte nuclear factor 4 alpha (Hnf $4 \alpha)$ were expressed at significant levels at the end of differentiation (day 20). The averaged expression level of hepatic markers observed from three replicate runs was comparable to that seen in differentiation carried out in 2D on culture plates (Fig. 3C). By FACS, $18 \%$ of the cells expressed asialoglycoprotein receptor (ASGPR-1), which is a type II transmembrane glycoprotein expressed on hepatocytes (Fig. 3D). Albumin secretion rate was $0.06 \pm 0.03 \mathrm{pg} /$ cell/day (Table 2). Urea was produced at $17.9 \pm 5.8 \mathrm{pg} / \mathrm{cell} /$ day (Table 2). Thus, MAPC on microcarriers can be differentiated into hepatocytelike cells as shown by the up-regulation of hepatic-genes and the secretion of albumin and urea.

\subsubsection{Differentiation in stirred suspension culture}

Next, MAPC were expanded in microcarrier culture in a spinner flask and directed differentiation to hepatic lineage was carried out subsequently. MAPC were inoculated at $3.1 \times 10^{4}$ cells $/ \mathrm{ml}$ with $0.6 \mathrm{mg} / \mathrm{ml}$ of Cytodex 1 microcarriers. Upon reaching $80-90 \%$ confluent and a cell concentration of $3.0 \times 10^{5}$ cells $/ \mathrm{ml}$, MAPCladen-microcarriers were washed with PBS once and resuspended in differentiation medium as prescribed by differentiation protocol. The cell concentration increased to $6.7 \times 10^{5}$ cells $/ \mathrm{ml}$ after day 1 and then decreased to $4.2 \times 10^{5}$ cells $/ \mathrm{ml}$ after treatment in Activin $A$ and Wnt3a for 6 days. The concentration again increased up to $6.8 \times 10^{5}$ cells $/ \mathrm{ml}$ on day 10 , then decreased again towards the end. Morphological changes of the cells seen in the bioreactor were similar to those seen in static culture. Bulges of cells on microcarriers were also seen and their size increased (Fig. 4). After 20 days of hepatic differentiation, cells retained high viability.

We also monitored gene expression involved during hepatic differentiation in the spinner flask culture. Transcript levels of the definitive endoderm genes, Goosecoid (Gsc), Chemokine (C-X-C motif) receptor 4 (Cxcr4), Mix1 homeobox-like 1 (Mixl1), and Eomesodermin homolog (Eomes) peaked on day 6 indicating the MAPCs were committed to definitive endoderm stage as expected in hepatic differentiation (Fig. 5). Transcripts for hepatic endoderm genes, Afp and Ttr, increased from day 6 onwards and were maintained at a high level throughout the differentiation process. Transcripts for the more mature hepatic-genes Albumin, Aat, Tat, G6p, Mgst1, Factor $V$, Arginase 1 , and $H n f 4 \alpha$ increased significantly by day 20 of the hepatic differentiation. The expression level of mature transcripts was comparable to that in static differentiation. In addition, differentiated cells at day 20 secreted albumin at $1.03 \mathrm{pg} / \mathrm{cell} /$ day, or about $12 \%$ of the level secreted by adult rat hepatocytes, and urea was secreted at $17.4 \mathrm{pg} / \mathrm{cell} /$ day (Table 2). These results suggest that hepatic differentiation on microcarriers in stirred suspension culture can provide hepatic cells in a larger scale.

\section{Discussion}

Much progress has been made in directed hepatic differentiation of various stem cells, including human and mouse embryonic stem cells (ESCs) and induced pluripotent stem cells (iPS cells) in the past few years (Sancho-Bru et al., 2009; Si-Tayeb et al., 2010; Song et al., 2009). The achievements have renewed the hope that cell transplantation or bioartificial liver devices involving stem cell-derived hepatocytes may be getting closer to reality. The recent demonstration of iPS cell differentiation to hepatocyte-like cells also raises the prospect that iPS cells derived from patients of different genetic background can be differentiated into hepatocytes and used for toxicity and metabolic studies. These advances heighten hopes as well as highlight the need for the development of robust bioprocesses, which are capable of producing large numbers of stem cells or their hepatic progenies appropriate for various applications.

The feasibility of cultivating different stem cells has been demonstrated for various types of bioreactors such as perfusion reactors, rotating vessels, spinner reactors, and others (Cameron 
(A)

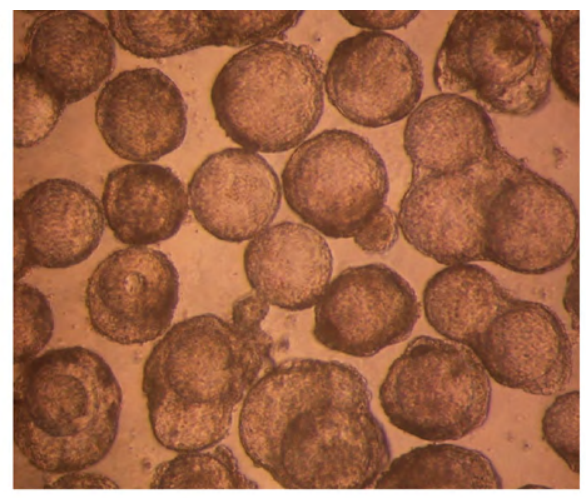

(B)

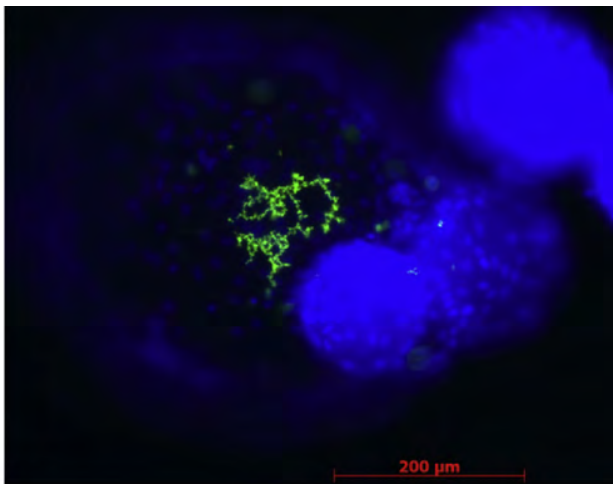

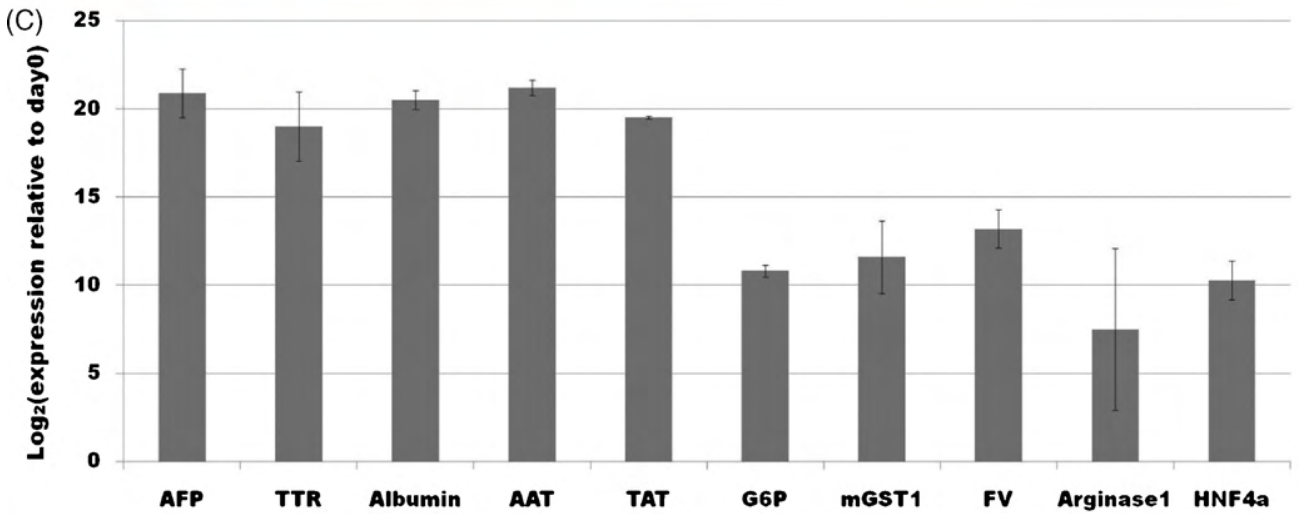

(D)

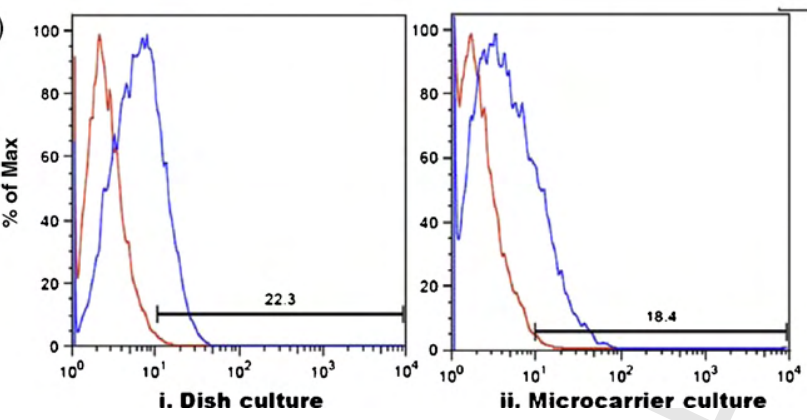

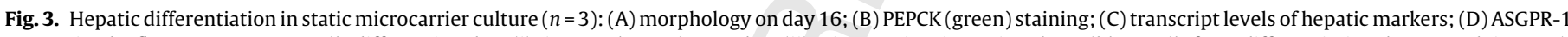

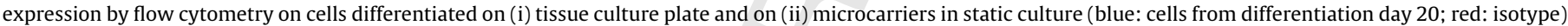
(For interpretation of the references to color in this figure legend, the reader is referred to the web version of the article.)

et al., 2006; Fok and Zanstra, 2005; Gilbertson et al., 2006; Li et al., 2006; Liu et al., 2006; Zhao et al., 2005; Bauwens et al., 2005; Schroeder et al., 2005). Ideally, a bioreactor should provide a homogeneous environment, for a high concentration of cells, and allow easy access for sampling. In this regard, a stirred vessel based system is superior to re-circulating flat-bed and rotating vessels. Some stem cells are capable of proliferation and/or differentiation when grown as aggregates, such as EBs from ESCs. Upon formation of such aggregates, they can be grown in a stirred bioreactor. However, not all cells can be cultivated as aggregates. Microcarrier culture combined with suspension culture systems allows the growth of adherent-dependent stem cells in high density.

Table 2

Albumin secretion and urea production rates from hepatic differentiation.

\begin{tabular}{llc}
\hline Rate $(\mathrm{pg} /$ cell/day $)$ & Static culture $(n=3)$ & Spinner culture $(n=1)$ \\
\hline Albumin & $0.06 \pm 0.03$ & 1.03 \\
Urea & $17.9 \pm 5.8$ & 17.4 \\
\hline
\end{tabular}

The microcarrier concentration used in this study was relatively low, and the culture was initiated with a relatively low inoculation cell concentration. Hence, we inoculated cells onto microcarriers under stationary conditions with a reduced volume to increase the microcarrier and cell concentrations, thereby increasing the probability of successful contacts between cells and microcarriers. The initial cell distribution on microcarriers greatly affects subsequent growth kinetics. Occasional mixing resulted in a better distribution of cells on the microcarriers. We observed that MAPCs attached relatively fast to microcarriers, comparable to the attachment of fibroblastic cells (Tao et al., 1987).

Rat MAPCs are typically cultured on fibronectin-coated dishes at a low initial density of 300 cells $/ \mathrm{cm}^{2}$ as it was thought that maintenance at a high density might result in differentiation and a corresponding loss of potency, as is observed for MSC culture (Breyer et al., 2006; Jiang et al., 2002; Javazon et al., 2004). Upon inoculating into a Cytodex 1 microcarrier culture, even without fibronectin coating, MAPC readily attach to microcarriers and proliferate at a growth rates similar to that seen on tissue culture plates (Fig. 1).Eventually MAPC form multiple layers on microcarriers and, 
(A)

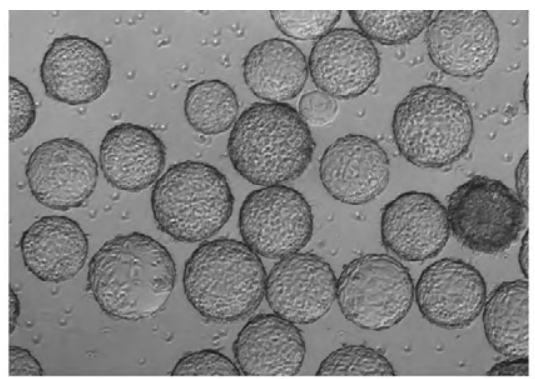

(C)

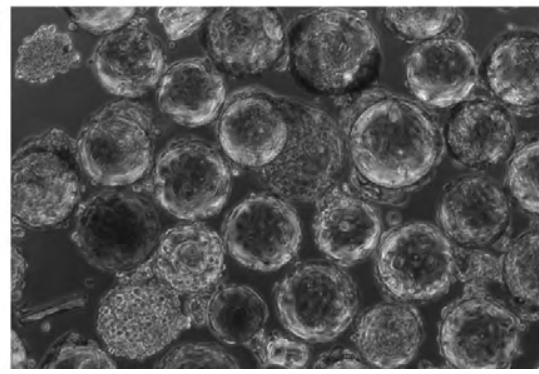

(B)

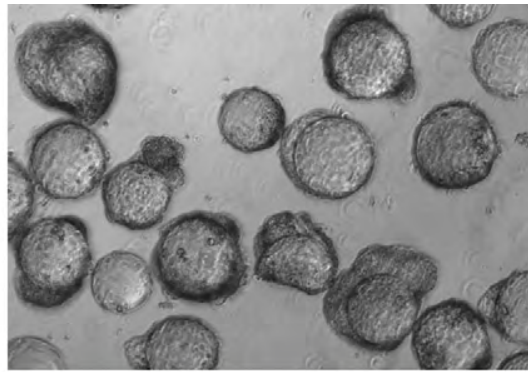

(D)

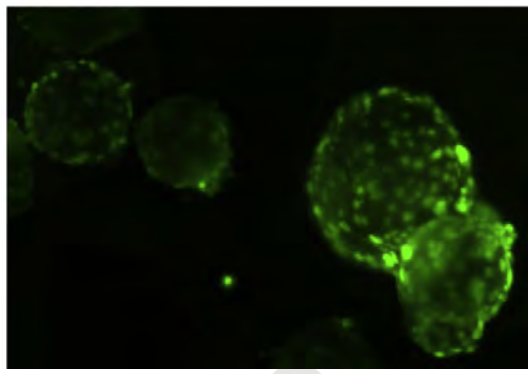

Fig. 4. Morphology of cells during hepatic differentiation: (A) day 0; (B) day 14; (C) day 20; (D) vitality staining on day 20 cells.

their doubling time increased from 14 to $24 \mathrm{~h}$. This result agrees with previous studies involving MAPC aggregate and mESC aggregate cultures; the doubling time of MAPC grown as aggregates is about $23 \mathrm{~h}$ (manuscript submitted), and a similar increase in doubling time was also noted when mESCs were cultured as aggregates (Fok and Zanstra, 2005). It is possible that cells grown as multilayers on microcarriers actually resemble cells in aggregates in terms of morphology, structure, and physiological characteristics.

The high cell density seen on microcarriers did not affect the potency of MAPC over the short reactor culture period. The cells continued to express the high levels of Oct4-transcripts and protein, a transcription factor expressed in early embryonic development and which is in ESCs essential for the maintenance of pluripotency. We have also shown that the level of Oct4-transcripts and protein in MAPC is correlated with the potency of the cells (Ulloa-Montoya et al., 2007). Other pluripotency-related markers of MAPC, namely Rex1, Sall4, and CD31, were expressed in MAPC in microcarrier stirred bioreactor culture at levels comparable to cells maintained at low density in 2D cultures. We also did not detect increased expression of genes closely associated with differentiation such as Sox2, Pax6, Flk1, and Afp (Fig. 2). Slight up-regulation of Sox2 and Flk1 was observed on day 4 of expansion culture. We speculate that this increased expression may be attributed to the high cell density within the multiple cell layers on the microcarrier beads. Similar phenotype, with no apparent loss differentiation potency, has also been observed in our MAPC aggregates and other systems (Purpura et al., 2008; Rizzino, 2009) (Subramanian et al., submitted). As Pax6 transcript level was not increased during expansion, with the slight
(A)

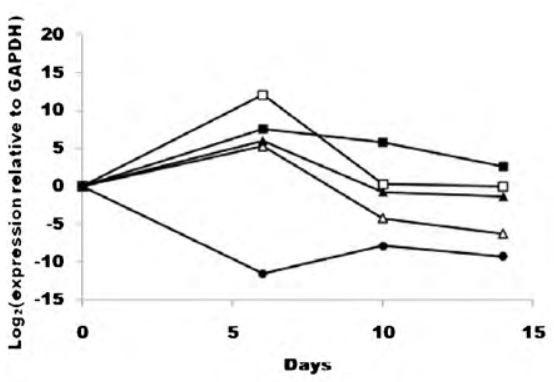

(B)

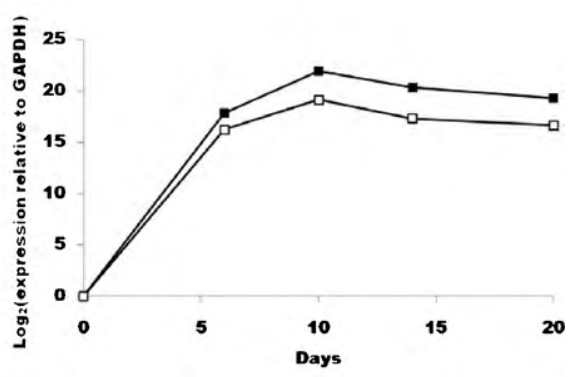

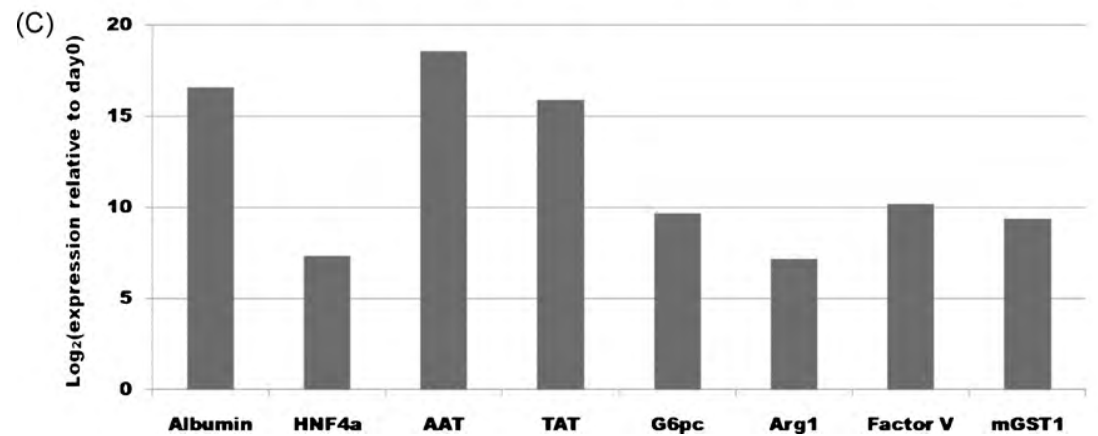

Fig. 5. Hepatic differentiation in spinner microcarrier culture $(n=1)$. Transcript levels of (A) Oct4 $(\bullet)$ and definitive endoderm markers Cxcr4 ( $\square$ ), Mixl1 ( $\square)$, Eomes ( $\mathbf{\Lambda})$, Gsc $(\triangle)$; (B) hepatic endoderm markers Afp ( $\square$ ), $\operatorname{Ttr}(\square)$; (C) mature hepatic markers from day 20. 
increase of only Sox2, an early commitment to the neuroectoderm lineage is unlikely.

Along with maintenance of MAPC potency during expansion, we used microcarrier culture systems for hepatocyte differentiation. This culture system allows large-scale hepatic differentiation; about $4 \times 10^{7}$ cells with hepatic phenotype and functions were obtained from $80 \mathrm{ml}$ culture. The extent of differentiation into hepatocyte-like cells on microcarriers, as judged by expression of various hepatocyte-specific genes, was similar to that seen in differentiation in 2D or in 3D in culture dishes (Roelandt et al., 2010). Furthermore, the dynamics of liver-specific gene expression profiles were similar in both microcarrier and dish cultures. Definitive endoderm transcripts (Gsc, Cxcr4, Mixl1, and Eomes) peaked during the earlier phase (day 6 ) of the differentiation, followed by expression of hepatic endoderm genes (Afp, Ttr) from day 6 onwards. Transcripts for mature hepatic-genes such as Albumin, Aat, Tat, G6p, Mgst1, Factor V, Arginase1, and Hnf4 $\alpha$ were significantly upregulated towards the end of hepatic differentiation (Fig. 5). This gene expression profile confirms that MAPC differentiate according to the known hepatic developmental stages, progressing from foregut endoderm, to fetal liver stem cells (hepatoblasts) and finally hepatocytes. The observation that cell number decreased initially from day 0 to day 6 is likely to be associated with the presence of Activin A in the differentiation medium at this stage, as observed in other studies (Fukuchi et al., 2001). The cell number subsequently increased from day 10 supporting the notion that this stage of differentiation corresponds to the hepatoblast stage of liver development. ASGPR-1, a surface molecule characteristic of the mature hepatocytes phenotype was used to quantify more mature hepatocyte-like cells. ASGPR-1 is known to be expressed in a smaller population of cells (18-22\%) than is Albumin in hESC hepatic differentiation (Basma et al., 2009). In MAPC microcarrier differentiation, about $20 \%$ of the cells were positive for ASGPR1 , a level similar to conventional two-dimensional differentiation (Fig. 3D). The cells also displayed hepatic functions; albumin and urea were secreted at the end of differentiation. The differentiated MAPC not only expressed albumin transcripts, but also secreted albumin at a rate of $1.03 \mathrm{pg} /$ cell/day, a level that was higher than that from culture dish differentiation ( $0.06 \mathrm{pg} /$ cell/day). Measured rates for both albumin and urea secretion are still lower than that of adult rat hepatocytes (Table 2) (Roelandt et al., 2010).

To further improve the microcarrier differentiation system, additional technical issues must be addressed. In our multi-step differentiation protocol, the differentiation medium with different cytokines is replaced periodically to drive the differentiation to the next stage. As the microcarriers used in this study were microporous, with a void fraction greatly exceeding $90 \%$, a large volume of residual medium from the previous differentiation stage is likely to remain in the interior of cell-laden microcarriers. It is not clear whether the residual components pose any significant effect on the outcome of differentiation. Because different signaling pathways are involved in committing cells in the different stages of differentiation to the next stage, it is possible that cytokines remaining from the previous step may have antagonistic effects on the ultimate levels of differentiation. The microcarrier concentration used in this study was low, and therefore the amount of residual components after medium replacement was also relatively small. However, in a differentiation bioprocess, with a higher microcarrier concentration, the effect of these residual cytokines may not be negligible. Using solid microcarriers that do not have internal pores can minimize the potential adverse effects. One can also speculate that microporous microcarriers may act as slow release reservoirs for potential trophic factors; however, such a function remains as speculation.

Another aspect of microcarrier application is the recovery of the cultured or differentiated cell products. Dissociation of cells from microcarrier surface followed by cell-microcarrier separation is likely to be a necessity in clinical and drug testing applications. Viable MAPCs can be easily detached from microcarriers with high recovery efficiency after a mild trypsin treatment. Differentiated cells can also be harvested while still retaining their function and viability. However, enzymatic treatments such as trypsinization and collagenase treatment on cell detachment can possibly cause disruption of critical cell surface proteins including ion channels, growth factor receptors and cell-cell junction proteins (Yang et al., 2005). This may bring subtle changes in cellular function and phenotype when cells are repeatedly passaged. For cell-bead dissociation and separation, various methods have been studied from mesh filter to employment of temperature-sensitive microcarriers (Billing et al., 1983; Gao et al., 2010; Yang et al., 2009). Development of effective methods will be a crucial advancement allowing microcarriers to be successfully applied in large-scale stem cell expansion and directed differentiation processes.

We conclude that microcarrier suspension culture is a robust method for scale up of MAPC expansion and differentiation to the hepatic lineage. It will facilitate the transformation of the laboratory practice of stem cell culture to scalable bioprocesses generating hepatocyte-like cells at industrial scales for future clinical applications.

\section{Acknowledgement}

Kartik Subramanian was supported by a doctoral dissertation fellowship, University of Minnesota.

\section{References}

Agarwal, S., Holton, K.L., Lanza, R., 2008. Efficient differentiation of functional hepatocytes from human embryonic stem cells. Stem Cells 26, 1117-1127.

Allain, J., Dagher, I., Mahieu-Caputo, D., Loux, N., Andreoletti, M., Westerman, K. Briand, P., Franco, D., Leboulch, P., Weber, A., 2002. Immortalizatiion of a primate bipotent epithelial liver stem cell. Proc. Natl. Acad. Sci. U.S.A. 99, 3639-3644.

Basma, H., Soto-Guitierrez, A., Yannam, G.R., Liu, L., Ito, R., Yamamoto, T., Ellis, E., Carson, S.D., Sato, S., Chen, Y., Muirhead, D., Navarro-Alvarez, N., Wong, R.J., Roy-Chowdhury, J., Platt, J.L., Mercer, D.F., Miller, J.D., Strom, S.C., Kobayashi, N., Fox, I.J., 2009. Differentiation and transplantation of human embryonic stem cell-derived hepatocytes. Gastroenterology 136, 990-999.

Bauwens, C., Yin, T., Dang, S., Peerani, R., Zandstra, P.W., 2005. Development of a perfusion fed bioreactor for embryonic stem cell-derived cardiomyocyte generation: oxygen-mediated enhancement of cardiomyocyte output. Biotechnol. Bioeng. 90, 452-461.

Billing, D., Clark, J.M., Ewell, A.J., Carter, C.M., Gebb, C, 1983. The seperation of harvested cells from microcarriers: a comparison of methods. Dev. Biol. Stand. 55, p67.

Breyer, A., Estharabadi, N., Oki, M., Ulloa, F., Nelson-Holte, M., Lien, L., Jiang, Y. 2006. Multipotent adult progenitor cell isolation and culture procedures. Exp. Hematol. 34, 1596-1601.

Cai, J., Ito, M., Weterman, K.A., Kobayashi, N., Leboulch, P., Fox, I.J., 2000. Construction of a non-tumorigenic rat hepatocyte cell line for transplantation: reversal of hepatocyte immortalization by site-specific excision of the SV40 T antigen. J. Hepatol. 33, 701-708.

Cai, J., Zhao, Y., Liu, Y., Ye, F., Song, Z., Qin, H., Meng, S., Chen, Y., Zhou, R., Song, X Guo, Y., Ding, M., Deng, H., 2007. Directed differentiation of human embryonic stem cells into functional hepatic cells. Hepatology 45, 1229-1239.

Cameron, C., Hu, W.S., Kaufman, D.S., 2006. Improved development of human embryonic stem cell-derived embryoid bodies by stirred cessel cultivation. Biotechnol. Bioeng. 94, 938-948.

Chiu, B., Wan, J.Z.M., Abley, D., 2005. Induction of vascular endothelial phenotype and cellular proliferation from human cord blood stem cells cultured in simulated microgravity. Acta Astronaut. 56, 918-922.

Fernandes, A., Fernandes, T.G., Diogo, M.M., 2007. Mouse embryonic stem cell expansion in a microcarrier-based stirred culture system. J. Biotechnol. 132, 227236.

Fok, E., Zanstra, P.W., 2005. Shear-controlled single step-mouse embryonic stem cell expansion and embryoid body-based differentiation. Stem Cells 23, 13331342

Frauenschuh, S., Reichmann, E., Ibold, Y., Goetz, P.M., Sittinger, M., Ringe, J., 2007. A microcarrier-based cultivation system for expansion of primary mesenchymal stem cells. Biotechnol. Progr. 23, 187-193.

Fukuchi, Y., Kizaki, M., Yamato, K., Kawamura, C., Umezawa, A., Hata Ji, Nishihara, T. Ikeda, Y., 2001. Mcl-1, an early-induction molecule, modulates activin A-induced apoptosis and differentiation of CML cells. Oncogene 20, 704-713. 
Gao, N., Wang, H.J., Yang, E.H., 2010. An experimental study on ferromagnetic nickel nanowires functionalized with antibodies for cell separation. Nanotechnology 21, p105107.

Gilbertson, J., Sen, A., Behie, L.A., Kallos, M.S., 2006. Scaled-up production of mammalian neural precursor cell aggregates in computer-controlled suspension bioreactors. Biotechnol. Bioeng. 94, 783-792.

Hay, D., Zhao, D., Fletcher, J., Hewitt, Z.A., McLean, D., Urruticoechea-Uriguen, A., Black, J.R., Elcome, C., Ross, J.A., Wolf, R., Cui, W., 2008. Efficient differentiation of hepatocytes from human embryonic stem cells exhibiting markers recapitulating liver development in vivo. Stem Cells 26, 894-902.

Herrera, M., Bruno, S., Buttiglieri, S., Tetta, C., Gatti, S., Deregibus, M.C., Bussolati, B. Camussi, G., 2006. Isolation and characterization of a stem cell population from adult human liver. Stem Cells 24, 2840-2850.

Javazon, E., Beggs, K.J., Flake, A.W., 2004. Mesenchymal stem cells: paradoxes of passaging. Exp. Hematol. 32, 414-425.

Jiang, Y., Jahagirdar, B.N., Reinhardt, R.L., Schwartz, R.E., Keene, C.D., Ortiz-Gonzalez, X.R., Reyes, M., Lenvik, T., Lund, T., Blackstad, M., Du, J., Aldrich, S., Lisberg, A., Low, W.C., Largaespada, D.A., Verfaillie, C.M., 2002. Pluripotency of mesenchymal stem cells derived from adult marrow. Nature 418, 41-49.

Kehoe, D., Jing, D.H., Lock, L.T., Tzanakakis, E.S., 2010. Scalable stirred-suspension bioreactor culture of human pluripotent stem cells. Tissue Eng. Part A 16, 405-421.

Li, Q., Liu, Q., Cai, H., Tan, W.S., 2006. A comparative gene-expression analysis of CD34+ hepatopoietic stem and progenitor cells grown in static and stirred culture systems. Cell Mol. Biol. Lett. 11.

Liu, Y., Liu, T., Fan, X., Ma, X., Cui, Z., 2006. Ex vivo expansion of hematopoietic stem cells derived from umblical cord blood in rotating wall vessel. J. Biotechnol. 124, 592-601.

Lock, L., Tzanakakis, E.S., 2009. Expansion and differentiation of human embryonic stem cells to endoderm progeny in a microcarrier stirred-suspension culture. Tissue Eng. Part A 15, 2051-2063.

Nie, Y., Bergendahl, V., Hei, D., Jones, J.M., Palecek, S.P., 2009. Scalable culture and cryopreservation of human embryonic stem cells on microcarriers. Biotechnol. Progr. 25, 20-31.

Oh, S., Chen, A.K., Mok, Y., Chen, X.L., Lim, U.M., Chin, A., Choo, A.B.H., 2009. Reuveny $\mathrm{S}$, long-term microcarrier suspension cultures of human embryonic stem cells. Stem Cell Res. 2, 219-230.

Purpura, K.A., George, S.H., Dang, S.M., Choi, K., Nagy, A., Zanstra, P.W., 2008. Soluble Flt-1 regulates Flk-1 activation to control hematopoietic and endothelial development in an oxygen-responsive manner. Stem Cells 26, 2832-2842.

Rizzino, A., 2009. Sox2 and Oct-3/4: a versatile pair of master regulators that orchestrate the self-renewal and pluripotency of embryonic stem cells by functioning as molecular rheostats. Wiley Interdiscip. Rev. Syst. Biol. Med. 1, 228-236.
Roelandt, P., Sancho-Bru, P., Pauwelyn, K., Verfaillie, C., 2010. Differentiation of rat multipotent adult progenitor cells to functional hepatocyte-like cells by mimicking embryonic liver development. Nature Protocols 5, 1324-1336.

Rogler, L., 1997. Selective bipotential differentiation of mouse embryonic hepatoblasts in vitro. Am. J. Pathol. 150, 591-602.

Sancho-Bru, P., Najimi, M., Caruso, M., Pauwelyn, K., Canz, T., Forbes, S., Roskams, T., Ott, M., Gehling, U., Sokal, E., Verfaillie, C.M., Muraca, M., 2009. Stem and progenitor cells for liver repopulation: can we standardise the process from bench to bedside? Gut 58, 594-603.

Schroeder, M., Neibruegge, S., Werner, A., Willbold, E., Burg, M., Ruediger, M., Field L.J., Lehmann, J., Zweigerdt, R., 2005. Differentiation and lineage selection of mouse embryonic stem cells in a stirred bench scale bioreactor with automated process control. Biotechnol. Bioeng. 92, 920-933.

Si-Tayeb, K., Noto, F.K., Nagaoka, M., Li, J.X., Battle, M.A., Duris, C., North, P.E., Dalton, S., Duncan, S.A., 2010. Highly efficient generation of human hepatocyte-like cells from induced pluripotent stem cells. Hepatology 51, 297-305.

Song, Z., Cai, J., Liu, Y.X., Zhao, D.X., Yong, J., Duo, S.G., Song, X.J., Guo, Y.S., Zhao, Y., Qin, H., Yin, X.L., Wu, C., Che, J., Lu, S.C., Ding, M.X., Deng, H.K., 2009. Efficient generation of hepatocyte-like cells from human induced pluripotent stem cells. Cell Res. 19, 1233-1242.

Tao, T., Ji, G.Y., Hu, W.S., 1987. Human fibroblastic cells attach to controlled-charge and gelating-coated microcarriers at different rates. J. Biotechnol. 6 (1), 9-12.

Ulloa-Montoya, F., Kidder, B.L., Pauwelyn, K.A., Chase, L.G., Luttun, A., Crabbe, A., Geraerts, M., Sharov, A.A., Piao, Y., Ko, M.S.H., Hu, W.S., Verfaillie, C., 2007. Comparative transcriptome analysis of embryonic and adult stem cells with extended and limited differentiation capacity. Genome Biol. 8, pR163.

Wege, H., Chui, M.S., Le, H.T., Strom, S.C., Zern, M.A., 2003. In vitro expansion of human hepatocytes is restricted by telomere-dependent replicative aging. Cell Transplant. 12, 897-906.

Yang, H., Seo, J.H., Kim, B.S., 2009. Serial propagation of cells on thermo-sensitive microcarrier. Tissue Eng. Regen. Med. 6, 1262-1267.

Yang, J., Yamato, M., Kohno, C., Nichimoto, A., Hidekazu, S., Fukai, F., Okano, T. 2005. Cell sheet engineering: recreating tissues without biodegradable scaffolds. Biomaterials 26, 6415-6422.

Yang, Y., Rossi, F.M.V., Putnins, E.E., 2007. Ex vivo expansion of rat bone marrow mesenchymal stromal cells on microcarrier beads in spin culture. Biomaterials 28, 3110-3120.

Zhao, F., Pathi, P., Grayson, W., Xing, Q., Locke, B.R., Ma, T., 2005. Effects of oxygen transport on 3D human mesenchymal stem cell metabolic activity in perfusion and static cultures: experiments and mathematical model. Biotechnol. Progr. $21,1269-1280$. 